\title{
APLICAÇ̃̃ DOS MÉTODOS GRAVIMÉTRICO E ELETRORESISTIVIMÉTRICO-IP EM ÁREA DE RISCO GEOTÉCNICO DO SISTEMA AQÜÍFERO CÁRSTICO EM ALMIRANTE TAMANDARÉ-PR
}

\author{
Jair Silveira da Silva Junior ${ }^{1}$, Francisco José Fonseca Ferreira ${ }^{2}$ e Rodoilton Stevanato ${ }^{3}$ \\ Recebido em 12 maio, 2006 / Aceito em 20 setembro, 2006 \\ Received on May 12, 2006 / Accepted on September 20, 2006
}

\begin{abstract}
The application of the gravity, resistivity and induced polarization (IP) methods on the geophysical interpretation in karst terrains is a useful tool, considering its capability in identifying and dimensioning existing dissolution features such as fractures, voids or cavities, filled or not by water or sediment in the subsurface. The bi-dimensional and three-dimensional modeling of these bodies makes possible an indirect evaluation of the geotechnical-structural context of the terrain under study. The aim of this work consisted on the identification of these features and the evaluation of their shape and dimensions over an area that suffered ground collapses, compromising buildings in this region. Qualitatively, the results indicated the existence of regions where there is water flow or very saturated soil, following the analysis of the correlation among the responses of the employed methods. In a quantitative point of view, gravity and resistivity-IP inversion methods were used. These methods allowed the estimation of the shape and the depth of the anomalies causative bodies. Finally, the results showed that the employed methods can be useful in the investigation of karst features, pointing out fragile regions which can compromise the implantation of physical structures over the surface.
\end{abstract}

Keywords: gravimetry, resistivity/IP, karst aquifer system, geotechnical risk.

RESUMO. A aplicação dos métodos gravimétrico, eletroresistivimétrico e da polarização induzida (IP), na interpretação geofísico-geológica de terrenos cársticos, tem se revelado útil, considerando a possibilidade de identificação e dimensionamento de feições de dissolução tais como fraturas, vazios ou cavidades, preenchidas ou não por água ou sedimentos, sob a superfície do terreno. As modelagens bidimensional e tridimensional destes corpos possibilitam a avaliação indireta do contexto estruturalgeotécnico do terreno em estudo. 0 objetivo do trabalho consistiu na identificação e avaliação das formas e dimensões destas feições em uma área que recentemente sofreu colapso de terreno, comprometendo edificações existentes na região. Qualitativamente, os resultados indicaram a existência de tratos onde potencialmente existe percolação de água, ou solo muito saturado, segundo a análise da correlação das respostas dos métodos empregados. Do ponto de vista quantitativo, métodos de inversão de dados gravimétricos e resistivimétricos-IP permitiram estimar a forma e a profundidade dos corpos causadores das anomalias. Finalmente, os resultados mostraram que os métodos empregados podem ser úteis na investigação de feições de dissolução, destacando regiões frágeis que podem comprometer a implantação de estruturas físicas na superfície.

Palavras-chave: gravimetria, resistividade/IP, sistema aqüífero cárstico, risco geotécnico.

Universidade Federal do Paraná, Laboratório de Pesquisas em Geofísica Aplicada (LPGA/UFPR), Centro Politécnico, Jardim das Américas, Caixa Postal 19045, 81531-980 Curitiba, PR, Brasil. Tel/Fax: (41) 3361-3132.

1 in memorian

2E-mail: francisco.ferreira@ufpr.br

3E-mail: rodoilton@ufpr.br 


\section{INTRODUÇÃo}

A ocupação da Região Metropolitana de Curitiba (RMC) concentrou-se inicialmente sobre as unidades geológicas correspondentes à Bacia Sedimentar de Curitiba e sedimentos aluvionares da bacia hidrográfica do Alto Iguaçu. Nos últimos anos, porém, a expansão urbana da RMC deu-se de forma muito rápida, fazendo com que a Capital ficasse conurbada a seus municípios vizinhos. Essa expansão avançou sobre os litotipos da Formação Capiru do Grupo Açungui, particularmente em suas rochas metacarbonatadas, situadas ao norte da cidade de Curitiba (Polidoro, 2005).

Uma das conseqüências desta expansão foi a crescente demanda por recursos hídricos, visando o abastecimento de grande parte da população da RMC. Todavia, tal demanda tem sido comprometida tanto por causa da poluição desencadeada pela ocupação urbana como pelo próprio volume de água requerido para 0 abastecimento público. Esta combinação de fatos provocou a busca por águas subterrâneas, armazenadas nos mármores do Grupo Açungui, constituintes principais do chamado Sistema Aqüífero Cárstico - SAC.

Apesar do SAC constituir uma opção tecnicamente segura e com custos reduzidos para 0 abastecimento público da região norte da RMC (Lisboa, 1997), as regiões cársticas são instáveis do ponto de vista geotécnico e a explotação de águas subterrâneas, sem 0 adequado conhecimento da dinâmica hidrogeológica do sistema, pode causar problemas sócio-econômicos e ambientais. Dentre eles destacam-se a subsidência e o colapso do terreno, rebaixamento do nível de água subterrânea ao longo dos anos, decréscimo da produção dos poços, redução da umidade do solo e seus reflexos na vegetação natural, ou cultivada, além da interferência nos mananciais de superfície e desequilíbrio dos ecossistemas relacionados.

No presente trabalho foi desenvolvido um estudo, baseado na aplicação de métodos geofísicos, em determinado trato de interesse localizado no município de Almirante Tamandaré-PR, cuja área territorial encontra-se quase 80\% sobre terrenos cársticos. Os métodos em questão compreenderam a gravimetria em conjunto com ensaios de resistividade elétrica e de polarização induzida (IP), com o intuito de averiguar as condições geotécnicas do terreno, através da caracterização qualitativa e quantitativa das estruturas geológicas (vazios, cavidades e fraturas).

Usando gravimetria e eletrorresisitividade/IP, pretendeu-se identificar as principais feições existentes na área de estudo e também quantificar suas formas e dimensões com base em processos de inversão de dados gravimétricos, de resistividade aparente e de cargabilidade aparente. Para tanto, foi selecionada uma área-alvo localizada na sede do município de Almirante Tamandaré (RMC), especificamente ao entorno do Colégio Estadual Ambrósio Bini, o qual sofreu danos em sua edificação, decorrentes de subsidência e colapso do terreno, implicando em sua interdição no ano de 2001. Portanto, a pesquisa visou, além de avaliar a aplicabilidade dos citados métodos, fornecer subsídios para a tomada de decisões por parte de órgãos públicos.

\section{LOCALIZAÇÃO DA ÁREA DE ESTUDO E DOS ENSAIOS GEOFÍSICOS}

A Figura 1 apresenta a localização do município de Almirante Tamandaré, situado na RMC, estado do Paraná. A área do município está situada integralmente sobre rochas metacarbonáticas da Formação Capiru (Grupo Açungui) e depósitos recentes do Terciário/Quaternário.

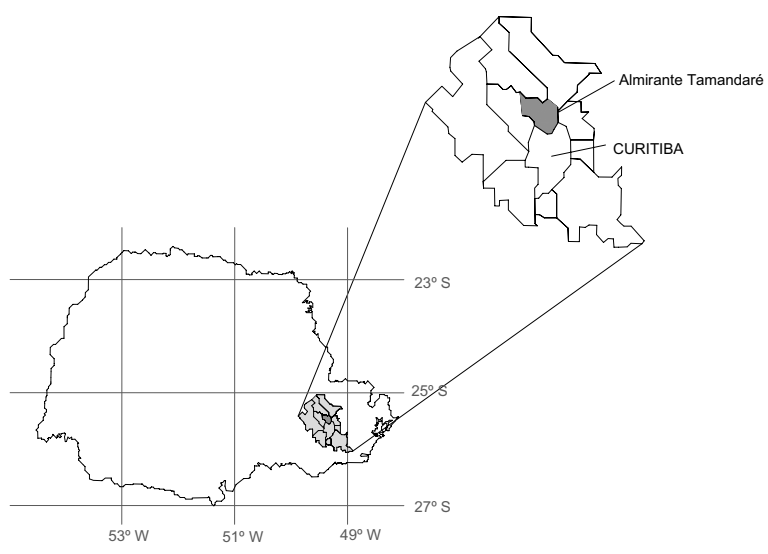

Figura 1 - Localização do município de Almirante Tamandaré em relação à Região Metropolitana de Curitiba (RMC) e ao estado do Paraná.

A Figura 2 ilustra a configuração geológica da região central do município, destacando a área do Colégio Estadual Ambrósio Bini, estudada no presente trabalho.

A área ao entorno do Colégio Estadual Ambrósio Bini, sede do município, sofreu colapso de sua estrutura física no ano de 2001, do que decorreu a interdição da edificação. A área levantada neste alvo é de $11.600 \mathrm{~m}^{2}$, na qual foram implantadas 417 estações gravimétricas, dispostas segundo uma malha quadrada de $5 \times 5 \mathrm{~m}$, envolvendo 24 linhas. Também foram realizadas 10 sondagens elétricas verticais (SEVs), espaçadas de 5 metros (arranjo Schlumberger), e 550 metros de caminhamento elétrico- $I P$ (arranjo dipolo-dipolo, $\mathrm{AB}=\mathrm{MN}=10 \mathrm{~m}$ ), este último envolvendo 5 linhas separadas de 10 metros. A localização dos ensaios geofísicos é indicada na Figura 3. Embora já tenham sido realizadas perícias técnicas no local objetivando averiguar causas e apontar soluções para o problema, os estudos geofísicos têm caráter inédito na localidade. 


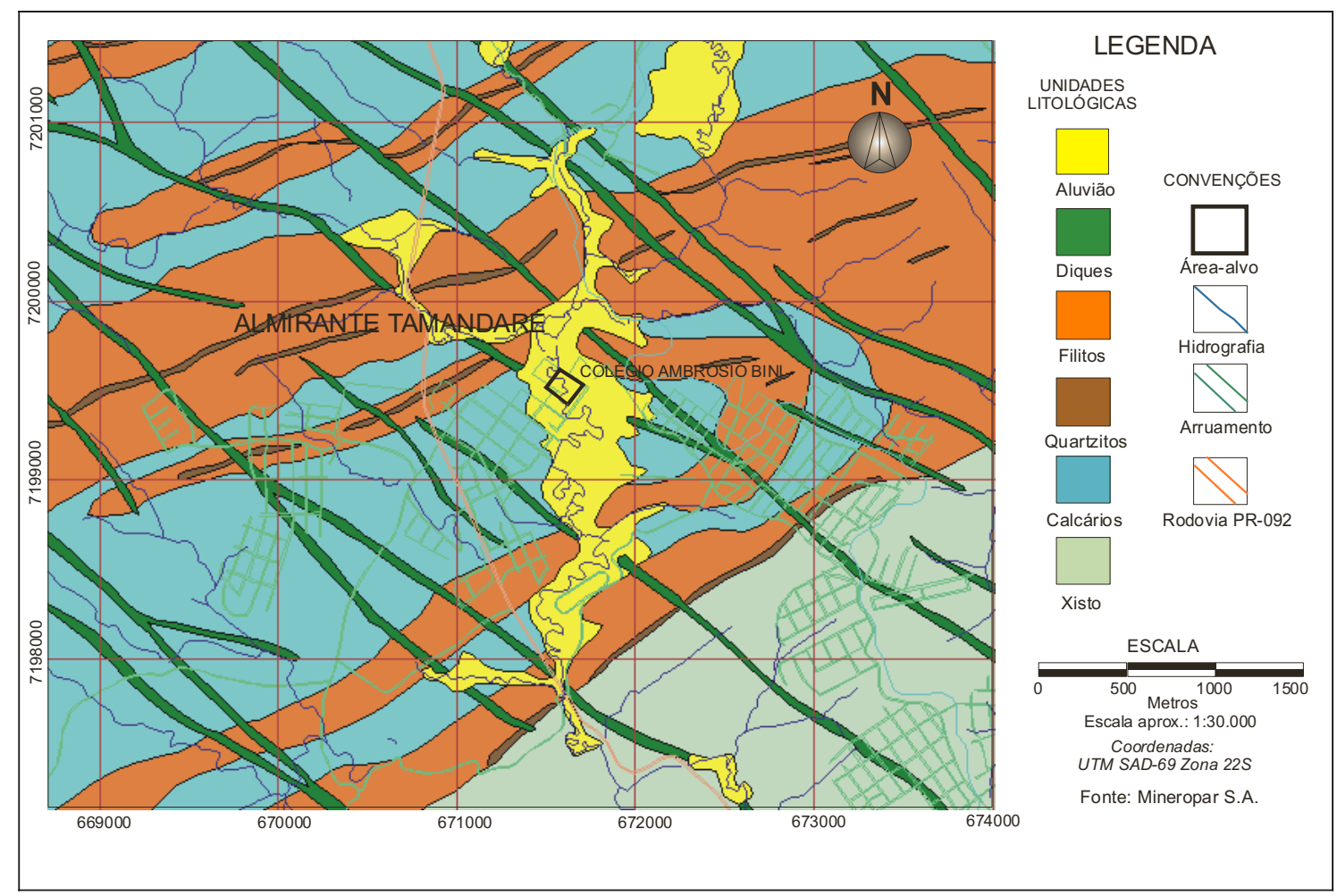

Figura 2 - Mapa litológico da região central do município de Almirante Tamandaré, indicando a localização da área do Colégio Estadual Ambrósio Bini (adaptado de Mineropar, 2005).

Estes estudos visam, principalmente, a identificação de feições geológicas que permitam associar os colapsos ocorridos na região com a percolação das rochas calcárias pelas águas do Iençol freático/subterrânea e possível desequilíbrio do SAC, provocado pela explotação no referido sistema. Ao lado do prédio onde funcionava 0 colégio existem dois poços de extração de água subterrânea (Fig. 3), da Companhia de Saneamento do Paraná - Sanepar, em cuja área os ensaios geofísicos também foram realizados.

\section{MÉTODOS GEOFÍSICOS APLICADOS À IDENTIFICAÇÃO DE FEIÇÕES CÁRSTICAS}

Métodos geofísicos de superfície podem ser empregados para mapear fraturas, cavidades e outras feições cársticas, com a característica de não serem invasivos. Dependendo das propriedades físicas ou químicas do meio, os métodos geofísicos podem detectar direta ou indiretamente a presença de feições de dissolução em um determinado local (Technos Inc., 2005).

Um dos métodos empregados atualmente para identificação de feições cársticas é a gravimetria. A técnica de microgravimetria consiste em medir variações no campo da gravidade ter- restre, associada a curtos intervalos de amostragem, visando a interpretação de vazios e cavidades em subsuperfície.

Anomalias gravimétricas geradas por feições de dissolução são sobrepostas a variações maiores devido ao contexto geológico regional, e, virtualmente, podem não ser detectáveis em investigações gravimétricas convencionais. Estas anomalias não apenas revelam a localização de tais feições, mas também fornecem informações a respeito de suas formas e profundidades. Este método tem sido largamente empregado em investigações de engenharia para detectar cavidades naturais ou antrópicas.

Estudos microgravimétricos realizados por Crawford (2000) nos Estados Unidos da América, país onde sistemas cársticos cobrem 20\% de seu território (Karst Water Institute, 2006), apresentaram ótimos resultados na detecção de vazios e na investigação de colapsos sob rodovias no estado de Kentucky. Para identificar pequenas variações no campo da gravidade devem ser tomadas medidas com grande precisão, em estações separadas de 1 a 5 metros, ao longo de um perfil ou malha regular. Crawford (2000) utilizou gravímetros relativos de alta precisão (Lacoste \& Romberg modelo D e o modelo CG-3M da Scintrex), ou microgravímetros, cujas resoluções de leitura chegam a 0,001 mGal. 


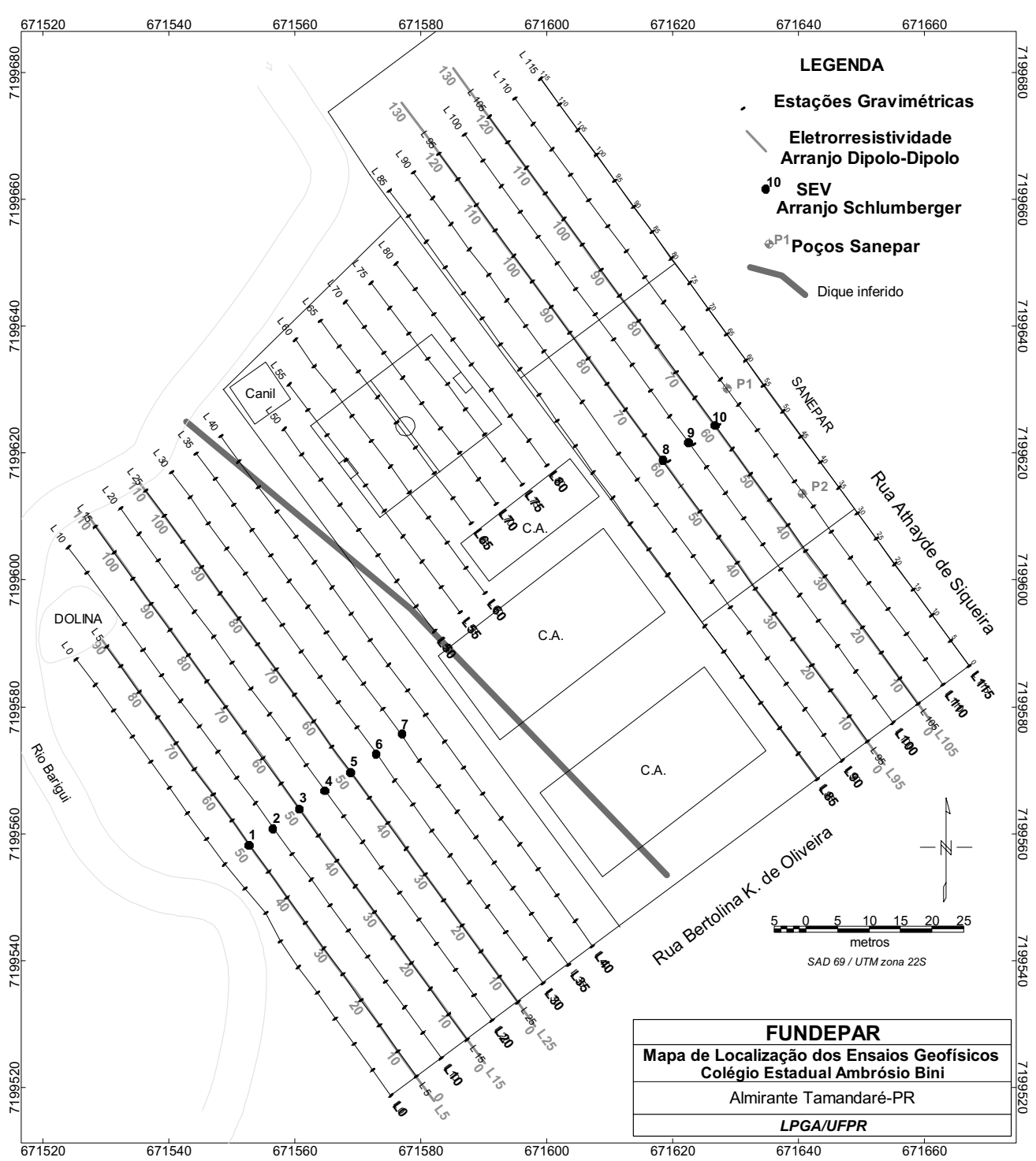

Figura 3 - Mapa de localização dos ensaios geofísicos.

Colley (1963) e Arzi (1975) apresentaram ainda alguns exemplos dos primeiros trabalhos de gravimetria realizados com o fim de identificar feições cársticas. Fajklewicz (1976) descreveu a aplicação de medidas do gradiente vertical da gravidade para a detecção de túneis e cavernas em cidades na Polônia. Butler (1984) aplicou microgravimetria para delinear uma cavidade vazia rasa (com menos de 10 metros de profundidade) e outra preenchida por água (a 30 metros abaixo da superfície), no estado da Flórida (EUA). Al-Rifaiy (1990) usou a microgravimetria para detectar cavidades em uma região calcária próxima à cidade do Kuwait.
Outros métodos também empregados em sistemas cársticos são 0 da eletrorresitividade e 0 da polarização induzida-IP. Estes métodos costumam ser empregados em conjunto, para melhorar a interpretação geofísica. As informações dadas pelos perfis e mapas geoelétricos podem auxiliar na inversão gravimétrica fornecendo uma informação a priori a respeito dos principais parâmetros da estrutura que está sendo investigada, o que contribui grandemente para a sua modelagem/inversão tridimensional.

Branston \& Styles (2003) descreveram a aplicação da microgravimetria em conjunto com a resistividade elétrica para avaliar um caso de subsidência de terreno em uma zona residencial do 
município de Northwich, na Inglaterra. Neste trabalho foram realizados levantamentos gravimétricos em diferentes épocas, possibilitando monitorar a magnitude da subsidência do terreno.

No Brasil, dentre outros, Gallas \& Augusto Filho (1999) realizaram ensaios de eletrorresistividade- $I P$ e potencial espontâneo$S P$ em mármores de um loteamento no estado de São Paulo. Constataram que as anomalias de $S P$ e de resisitividade poderiam refletir zonas de maior percolação de água, associadas a fraturamentos e feições cársticas, ou mesmo maiores espessuras de solos coluvionares e aluvionares. Dourado et al. (2001) aplicaram o método gravimétrico em conjunto com ensaios de eletrorresistividade e GPR (Ground Penetrating Radar) para a detecção de cavidades em arenitos na região de Descalvado, estado de São Paulo. Os resultados mostraram-se coerentes, pois onde a gravimetria indicou ausência de massa, o caminhamento elétrico detectou um incremento de resistividade elétrica.

\section{Método gravimétrico}

A prospecção gravimétrica envolve medidas das variações do campo de gravidade terrestre. Deseja-se, com isso, identificar e caracterizar as massas locais de maior ou menor densidade que as formações encaixantes a partir de irregularidades do campo medido na superfície. Tais irregularidades, denominadas anomalias, são interpretadas como resultado das variações laterais na densidade dos materiais da subsuperfície, provocadas por estruturas geológicas ou corpos rochosos com diferentes densidades (Telford et al., 1990).

A interpretação do campo perturbador torna-se mais complicada devido ao fato de que a observação contém 0 efeito integral de todas as massas da Terra. Com o auxílio de informaç̃ões topográficas, geológicas e geofísicas, as influências das massas conhecidas podem ser removidas através de reduções. Em particular, procedimentos de filtragem são utilizados para separar os grandes comprimentos de onda (campo regional) e os curtos comprimentos de onda (campo residual) das anomalias (Gupta \& Ramani, 1980 apudTorge, 1989).

\section{Avaliação da resolução do método gravimétrico}

Para avaliar a resposta gravimétrica de um espaço vazio, pode-se utilizar um modelo de cavidade esférica, com dimensão, profundidade e contraste de densidade variáveis.

0 efeito provocado por este corpo em um determinado ponto da superfície é função da sua distância em relação ao centro de massa do corpo causador, do raio da esfera e do contraste de densidade com a rocha encaixante.
A amplitude da anomalia esperada deve ser maior que a acurácia do instrumento e precisão do levantamento. Considerando um corpo com um formato aproximadamente esférico, deseja-se estimar a profundidade máxima de ocorrência que 0 método gravimétrico é capaz de identificá-lo e quantificá-Io. Esta avaliação foi feita com base na equação (1), para um problema bidimensional (Telford et al., 1990):

$$
\Delta g=k \rho a^{3} \frac{z}{\left(x^{2}+z^{2}\right)^{3 / 2}}
$$

onde $k$ é uma constante igual a 0,$0279 ; \rho 0$ contraste de densidade, em $\mathrm{kg} / \mathrm{m}^{3} ; a$ raio da esfera; $z$ a profundidade ao centro do corpo e $x$ a distância do centro do corpo ao ponto considerado. As unidades $a$, $z$ e $x$ devem estar em metros.

As Figuras 4 e 5 apresentam um estudo realizado em função da variação da profundidade de ocorrência para corpos esféricos com raios de 2 e 5 metros, respectivamente, levando em consideração o material de preenchimento. Os valores correspondentes ao efeito provocado pelos corpos (eixo das ordenadas) estão em valores absolutos. A área verde corresponde à amplitude da anomalia que pode ser identificada segundo o método gravimétrico.

Nos exemplos acima, pode-se notar que uma cavidade com a configuração indicada pela curva vermelha dificilmente será identificada com 0 uso do método gravimétrico nos níveis de profundidade indicados. Porém, corpos que apresentam maiores contrastes de densidade serão melhor detectados conforme sua profundidade de ocorrência (Figs. 4 e 5).

\section{Métodos elétricos}

As medições de resistividade são normalmente feitas aplicandose uma corrente elétrica $(I)$ no terreno através de dois eletrodos $(\mathrm{A}$ e B) e medindo-se a diferença de potencial resultante $(V)$ em dois eletrodos de potencial ( $\mathrm{M}$ e N). A resistividade aparente é calculada a partir dos valores de corrente $(I)$ e do potencial $(V)$, obtidos segundo a expressão abaixo:

$$
\rho_{a}=k * \frac{V}{I}
$$

0 fator $k$ depende apenas da disposição dos eletrodos A, B, M e N. A resistividade aparente $\left(\rho_{a}\right)$ não é um parâmetro físico do meio, mas um efeito integrado sobre um segmento do semiespaço, para a qual contribuem os valores da resistividade em cada ponto e a disposição geométrica dos eletrodos. 


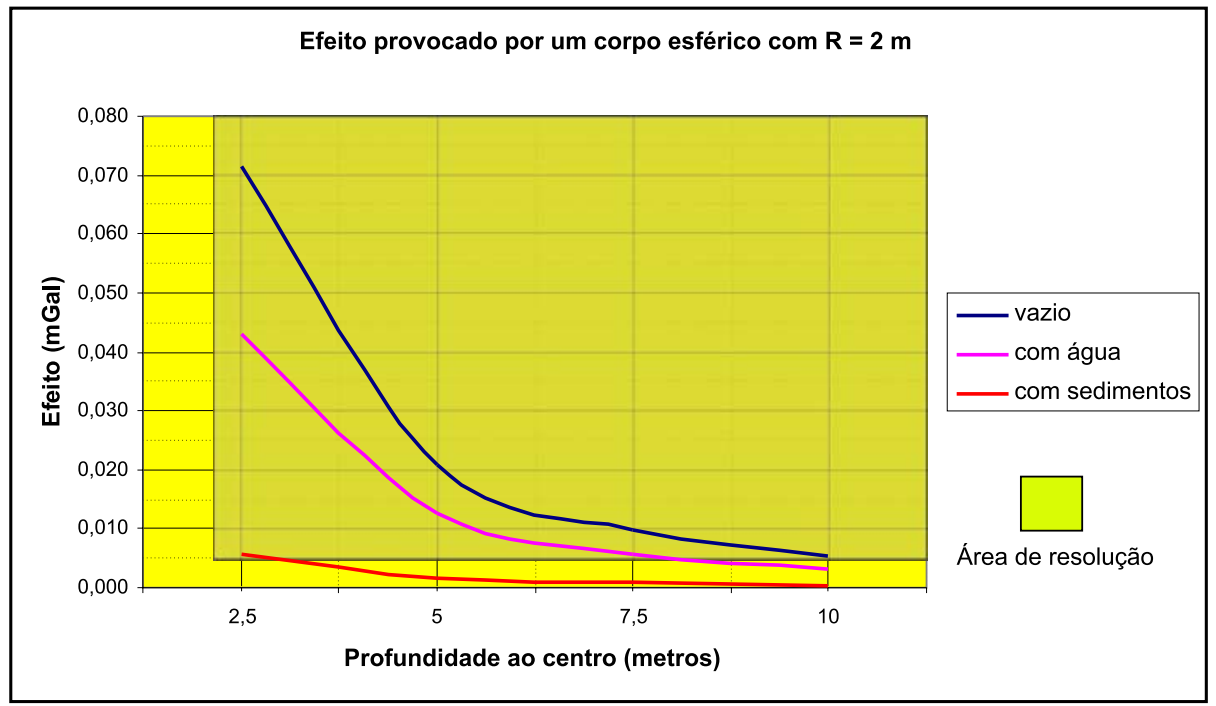

Figura 4 - Amplitudes máximas dos efeitos provocados por corpos esféricos de raio igual a 2 metros situados a diferentes profundidades e com distintos contrastes de densidade.

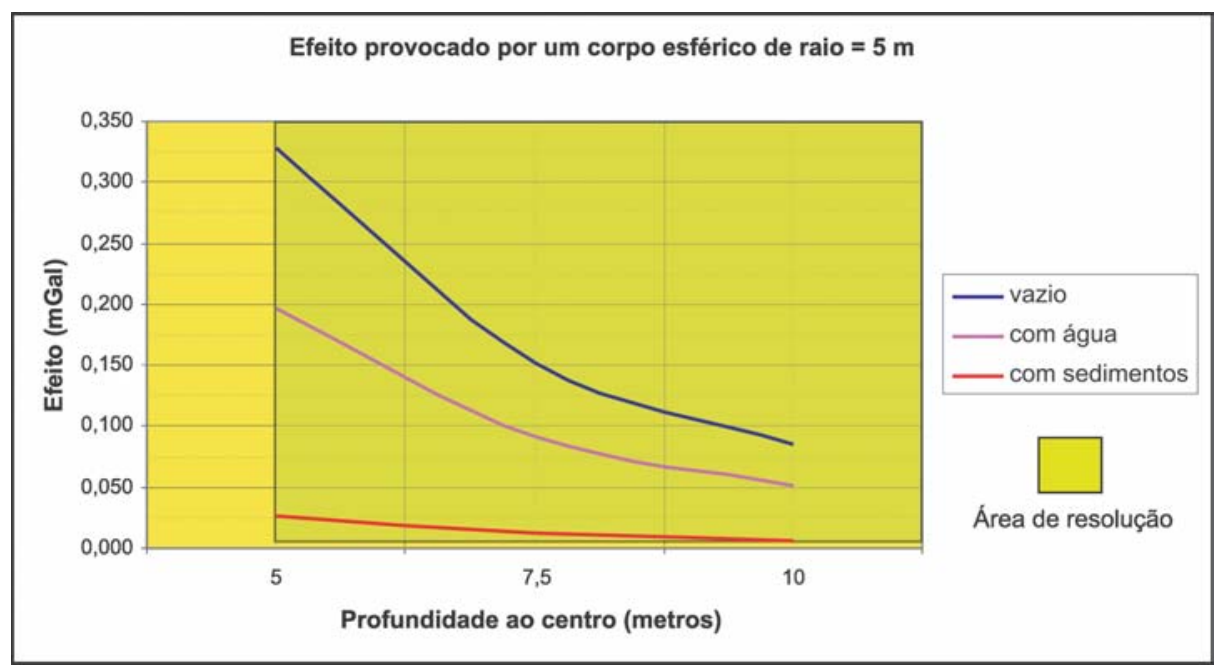

Figura 5 - Amplitudes máximas dos efeitos provocados por corpos esféricos de raio igual a 5 metros situados a diferentes profundidades e com distintos contrastes de densidade.

\section{Sondagem elétrica vertical (SEV) e caminhamento elétrico}

Na técnica de sondagem elétrica vertical (SEV), segundo o arranjo Schlumberger, o espaçamento dos eletrodos de potencial permanece praticamente fixo, enquanto a separação entre os eletrodos de corrente é expandida com o objetivo de obter-se informações mais profundas da seção geoelétrica. Para interpretar os dados de um levantamento deste tipo, normalmente pressupõe-se que a subsuperfície consiste de camadas planas horizontais. Neste caso, a resistividade varia apenas com a profundidade, mas não lateralmente, e um modelo unidimensional é usado para interpretar as medições. Apesar desta limitação, este método tem produzido resultados úteis em situações geológicas onde o modelo unidimensional é aproximadamente verdadeiro (profundidade do lençol freático, por exemplo). Outra técnica clássica de levantamentos de resistividade é o caminhamento elétrico (CE), normalmente utilizando o arranjo dipolo-dipolo. Nesta técnica 0 espaçamento entre os eletrodos permanece fixo, enquanto todo 0 arranjo é deslocado em linha reta. Tal técnica fornece informações sobre variações laterais e verticais de resistividade. 


\section{Polarização induzida - IP}

Quando uma corrente elétrica circula no terreno, podem surgir concentrações de carga em várias partes do semi-espaço que tendem a retornar à sua posição original quando a circulação de corrente é interrompida. Durante alguns segundos, uma determinada fração da voltagem inicial permanece no terreno enquanto as concentrações de cargas são dissipadas. Este fenômeno é conhecido como polarização induzida (induced polarization - IP).

A polarização induzida pode ser observada nos domínios do tempo e da freqüência. Apesar de ser complexo, 0 IP assemelhase à descarga de um capacitor (domínio do tempo) ou à variação de impedância de uma corrente alternada (domínio da freqüência).

Quando as medidas são feitas no domínio do tempo, como no presente trabalho, através do envio de pulsos de corrente no terreno, a magnitude da polarização induzida observada é freqüentemente expressa em $\Delta V / V$ (milivolt/volt), onde $\Delta V$ é a voltagem remanescente no instante $t$, depois do corte da corrente elétrica. $V$ é a voltagem medida enquanto a corrente circula. Esta medida de polarização induzida é expressa como uma porcentagem em termos de um parâmetro chamado polarizabilidade $(\eta)$. A voltagem de decaimento $V(t)$ é geralmente registrada durante um intervalo de tempo definido $\left(t_{1}, t_{2}\right)$. 0 resultado é expresso pela integral de tempo da medida de IP. A cargabilidade é um parâmetro comumente usado nas medidas no domínio do tempo. Sua unidade é o milivolt.segundo/volt $(m V s / V)$ (Sharma, 1997), ou genericamente milisegundo ( $m s$ ) e pode ser entendida como a razão de decaimento da voltagem inicial (ou voltagem secundária) pela voltagem primária.

\section{PROCESSAMENTO DOS DADOS GRAVIMÉTRICOS}

A primeira etapa do processamento, cujos dados foram adquiridos com o gravímetro CG-3 (AutoGrav, fabricação Scintrex), pertencente ao LPGA/UFPR, corresponde ao cálculo da deriva dinâmica, ou seja, a correção devida a variações no valor de $g$ provocadas pela movimentação do equipamento durante o levantamento. Em seguida são calculadas variações relativas de gravidade de cada estação em relação à estação base. 0 valor absoluto de $g$ na estação base é somado às medidas relativas, obtendose, assim, os valores absolutos de $g$ para cada estação.

As reduções free-air e Bouguer foram realizadas no software Oasis Montaj Geosoft (v. 6.2.0), módulo Xcelleration. Ao final deste processo são criadas automaticamente duas colunas no mesmo banco de dados contendo os valores das anomalias free-air e Bouguer. 0 último resultado constitui a base de dados empregada na interpretação e inversão gravimétrica. Devido à falta de informações altimétricas detalhadas das regiões externas à área do levantamento, a correção de terreno foi realizada utilizando apenas dados altimétricos restritos à área de estudo.

0 levantamento topográfico das linhas de levantamento foi realizado utilizando a técnica de nivelamento trigonométrico.

\section{Geração dos mapas de anomalias e de resíduos Bouguer}

A partir dos dados de anomalias Bouguer foi criada uma malha regular de 2,5 × 2,5 metros, através de interpolação numérica pelo método da curvatura mínima (Briggs, 1974). Este método interpola os dados através do ajuste de uma superfície bidimensional aos dados brutos $(x, y, z)$, de tal forma que a curvatura da superfície seja minimizada.

Para a geração do mapa de anomalias residuais foi realizada a separação regional-residual. Numericamente, esta operação foi implementada pela subtração de uma superfície de tendência de segundo grau às anomalias observadas. Com base nesses dados, uma nova malha (grid) foi calculada, utilizando também 0 método da curvatura mínima.

\section{Inversão gravimétrica}

0 método utilizado neste trabalho, desenvolvido por Cordell \& Henderson (1968), considera que as anomalias gravimétricas estejam dispostas em uma malha quadrada regular e que 0 corpo causador destas anomalias pode ser aproximado por um conjunto de prismas verticais elementares, cada um tendo a área de sua seção transversal igual à de uma célula da malha e com densidade uniforme. A posição vertical de cada elemento prismático é estabelecida através de uma relação sistemática com um plano horizontal de referência (Cordell \& Henderson, 1968).

A técnica de inversão adotada tem como base 0 programa GI-3, desenvolvido em linguagem de programação FORTRAN 77, cujo código-fonte é aberto e disponível à comunidade através do USGS - United States Geological Survey (USGS, 2005). Sua aplicação requer apenas um arquivo de comando, contendo os parâmetros iniciais do corpo (e.g. contraste de densidade e profundidade ao plano de referência) e um arquivo contendo as anomalias gravimétricas.

0 parâmetro de profundidade à superfície de referência foi estabelecido com base nos resultados dos modelos resistivimétricos. Outro parâmetro importante para a execução do programa é o contraste de densidade entre o corpo e as rochas encaixantes, 0 qual o programa não permite variar. No entanto, vários testes foram realizados variando a profundidade à base do corpo 


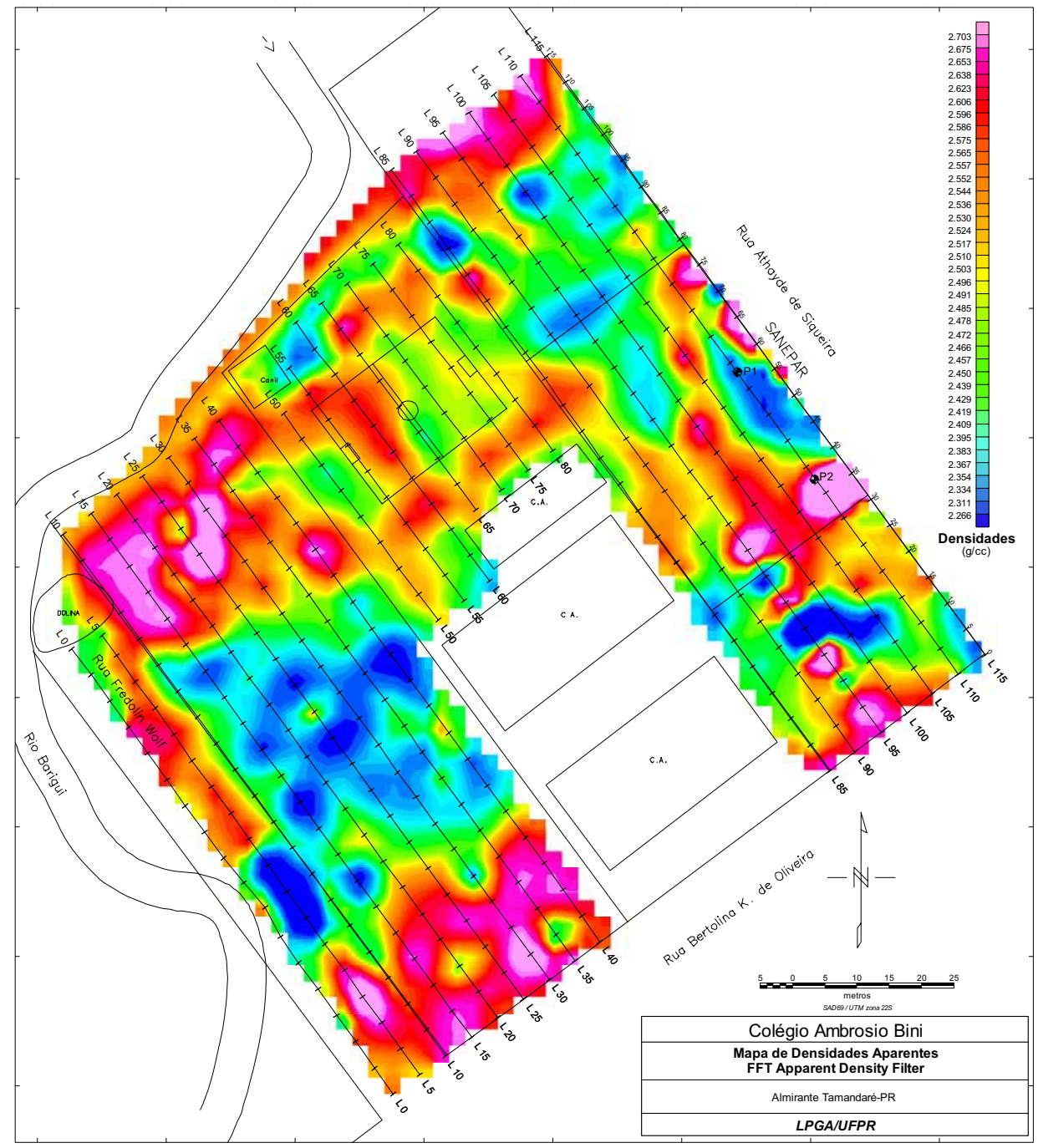

Figura 6 - Mapa de estimativas de densidade para a área do Colégio Estadual Ambrósio Bini.

e 0 contraste de densidade. A escolha do melhor modelo foi baseada no menor erro gravimétrico residual obtido.

\section{Estimativas de densidade aparente}

As estimativas de densidade aparente permitem avaliar 0 contraste de densidade, o qual é usado como parâmetro de entrada no algoritmo de inversão, bem como variar este valor baseado na estimativa realizada.

0 cálculo das densidades aparentes foi feito utilizando os vaIores das anomalias observadas. Os valores de densidade obtidos para a área de estudo foram calculados com 0 auxílio de um filtro específico para este fim, disponível no programa Oasis Montaj Geosoft. A Figura 6 apresenta os resultados obtidos por este processamento para a área do Colégio Estadual Ambrósio Bini.

\section{PROCESSAMENTO DOS DADOS GEOELÉTRICOS}

Os equipamentos utilizados na aquisição dos dados de resistividade aparente $\left(\rho_{a}\right)$ e de cargabilidade global aparente $\left(M_{a}\right)$, incluem um sistema completo de polarização induzida e resistividade, pertencente ao LPGA/UFPR, fabricado pela Iris Instruments, o qual é composto por um transmissor de alta potência (VIP3000W), alimentado por um gerador Honda (EM5000S), e um receptor multicanal/espectral (ELREC 10).

0 processamento dos dados dos caminhamentos elétricos/ polarização induzida, representados na forma de pseudoseções, foi realizado através dos pacotes Oasis Montaj ${ }^{\mathrm{TM}}$ e Zonge 2-D Inversion for Interactiv ${ }^{\mathrm{TM}}$ IP da Geosoft/Interpex. Este último pacote permite que os dados de resistividade/cargabilidade aparen- 


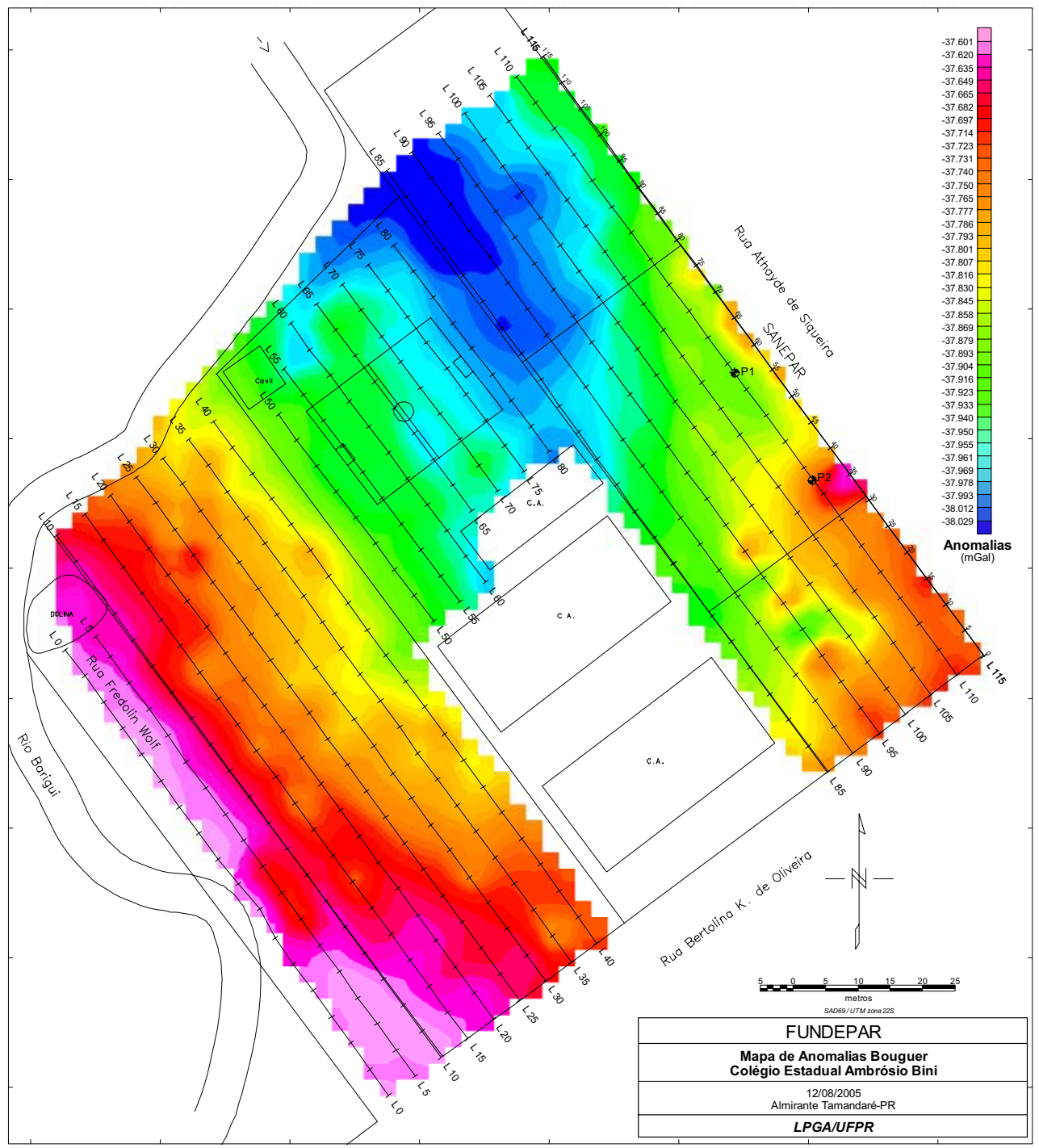

Figura 7 - Mapa de anomalias Bouguer da área do Colégio Estadual Ambrósio Bini.

tes, obtidos em seis níveis de investigação, sejam transformados em modelos representativos das resistividades/cargabilidades e das profundidades verdadeiras.

Os dados das sondagens elétricas verticais (SEVs) são representados em gráficos bi-logarítmicos. 0 pacote IPI2Win foi utilizado na inversão dos dados resistivimétricos das SEVs, o qual fornece o número de camadas e suas resistividades e profundidades verdadeiras.

\section{RESULTADOS}

As Figuras 7 e 8 apresentam os mapas de anomalias Bouguer e de resíduos correspondentes ao levantamento gravimétrico realizado na região do Colégio Estadual Ambrósio Bini.
A subárea indicada por um retângulo no mapa de anomalias residuais (Fig. 8), representativa de baixos gravimétricos, foi selecionada para inversão dos dados. Nesta etapa pretende-se investigar parâmetros que auxiliem na definição da forma e dimensões da estrutura geológica.

A Figura 9 mostra os resultados obtidos a partir da inversão gravimétrica tridimensional processada com auxílio do programa Gl-3, para a área do Colégio Estadual Ambrósio Bini, na qual foram adotados os valores de $-0,2 \mathrm{~g} / \mathrm{cm}^{3}$ para o contraste de densidade e de 5 metros para a profundidade de referência.

As Figuras 10 a 12 ilustram, respectivamente, as pseudoseções de resisitividade e cargabilidade global aparentes e os respectivos modelos de profundidade obtidos por inversão. As Fi- 


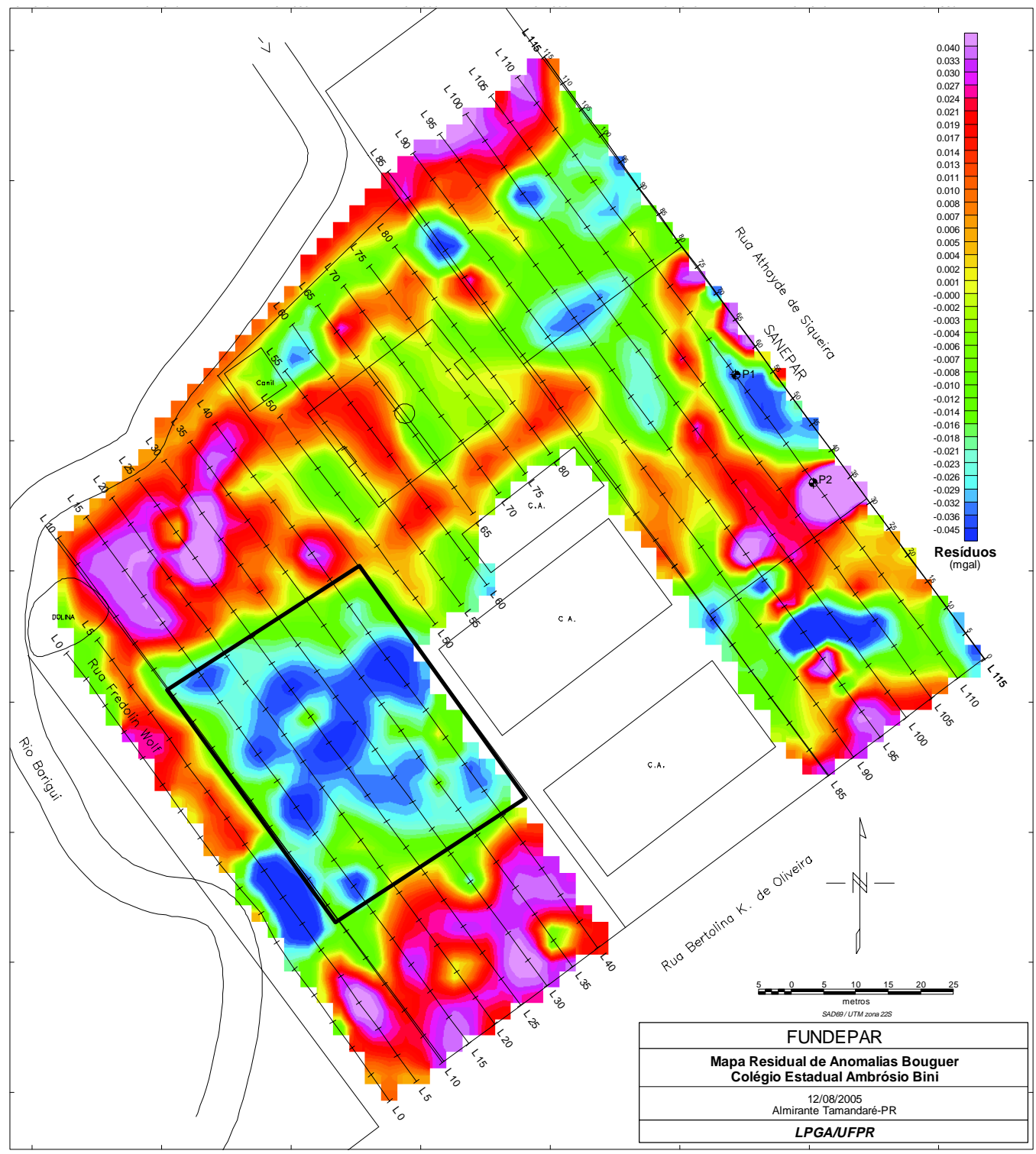

Figura 8 - Mapa residual de anomalias Bouguer indicando a área selecionada para a inversão gravimétrica.

guras 13 a 16 mostram as curvas de resistividade aparente das SEVs 1, 4, 6 e 8, e os respectivos modelos de profundidade obtidos por inversão, localizadas nas linhas de dipolo-dipolo L5, L20, L30 e L95 (Fig. 3). Foram selecionadas apenas quatro das dez SEVs realizadas, por se considerar que as mesmas representam suficientemente o conjunto estudado. A Figura 17 ilustra um perfil litológico segundo os resultados obtidos pelas sondagens elétricas verticais. Nela estão indicadas as profundidades e os litotipos inferidos pelas SEVs e também o perfil litológico real derivado dos dados dos poços P1 e P2 localizados na área de levantamento (Fig. 3).

\section{DISCUSSÃO}

A observação do mapa de anomalias Bouguer (Fig. 7), em correspondência à geologia local (Fig. 3), indica a existência de dois compartimentos distintos, pois a área do levantamento é interceptada ao meio por um dique de diabásio não aflorante, detectado por levantamentos magnéticos (Mineropar, 2005). No compartimento situado a sudoeste do dique, evidencia-se uma tendência linear das anomalias, afetadas por pequenas variações no campo, enquanto a nordeste nota-se um baixo gravimétrico mais intenso, com grandes comprimentos de onda. Tal constatação justifica a falta de continuidade da tendência linear das anomalias Bouguer. 


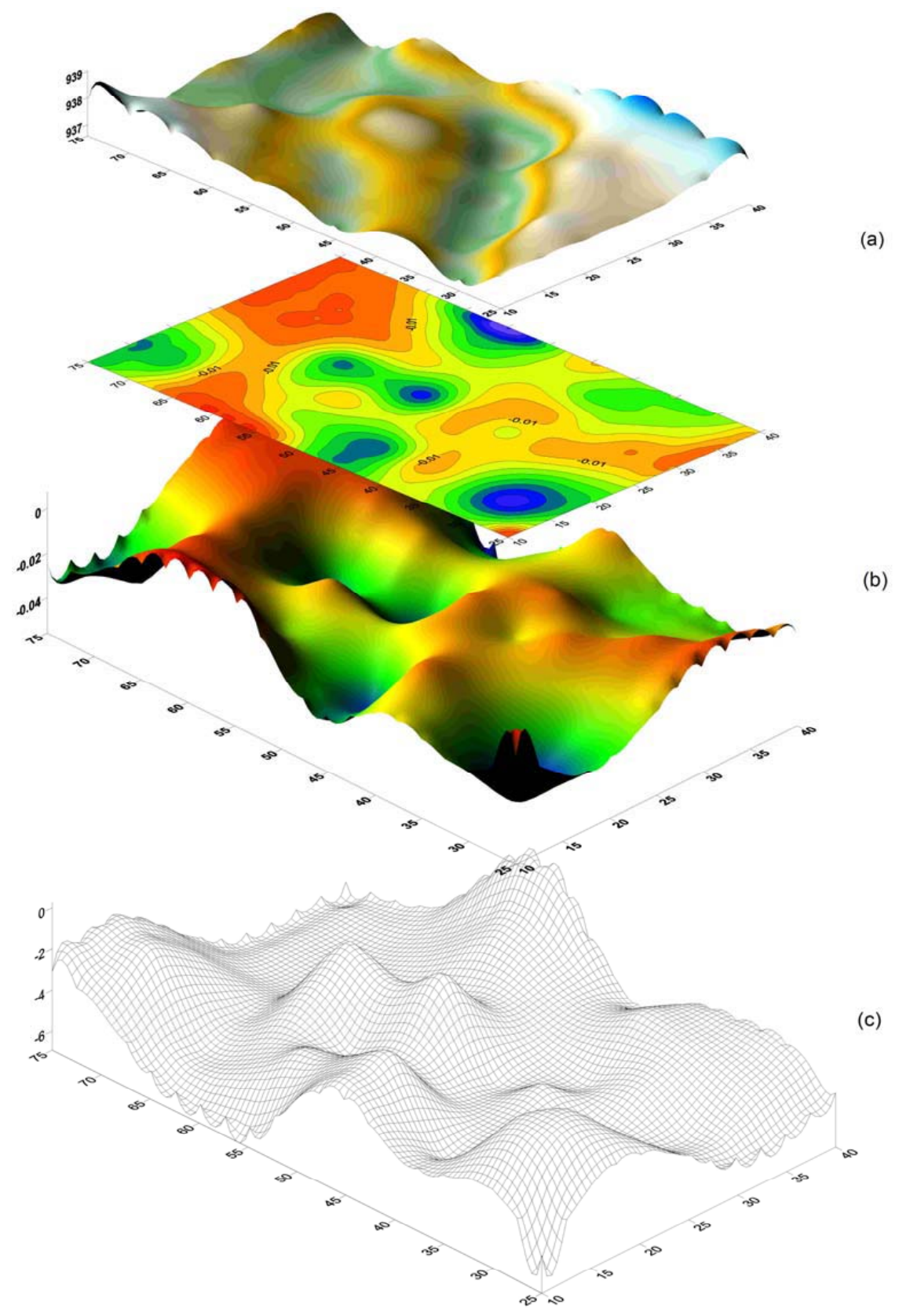

Figura 9 - Modelo gravimétrico obtido por inversão pelo programa Gl-3 na área do Colégio Estadual Ambrósio Bini. (a) superfície do terreno; (b) anomalias residuais observadas (representações plana e tridimensional); (c) superfície do modelo gerado por inversão.

0 mapa gravimétrico residual da Figura 8 apontou áreas com provável deficiência de massa (coberturas aluvionares e/ou eventuais fraturas/cavidades) localizadas tanto a sudoeste quanto a nordeste da edificação onde funcionava o colégio, assim como em locais isolados, como aquele na vizinhança do poço $\mathrm{P} 1$, além de outros situados a sul (Fig. 8). A presença de fontes rasas (baixos residuais), é corroborada pelos modelos de resistividade e cargabilidade. Neles (Figs. 10 a 12), nota-se, via de regra, a persistência de um estrato geoelétrico de baixa resistividade e cargabilidade, sotoposto a níveis resistivos e de cargabilidades em geral maiores (solo não saturado, espessuras até 5 metros), sugerindo a presença de água desde níveis superficiais ( \pm 5 metros) até profundidades da ordem de 15-20 metros, as quais constituíram aproximadamente os limites 
LINHA 5

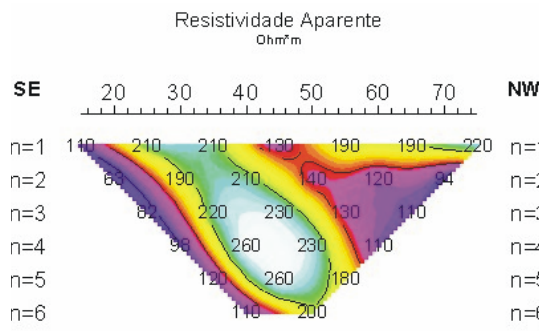

Resistividade Verdadeira

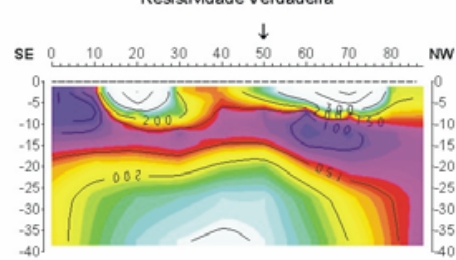

Cargabilidade Global Aparente

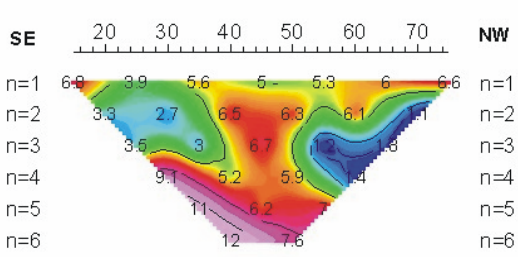

Cargabilidade Verdadeira

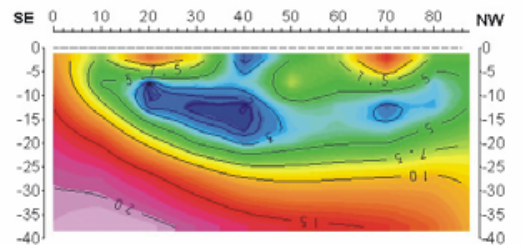

LINHA 15

Resistividade Aparente

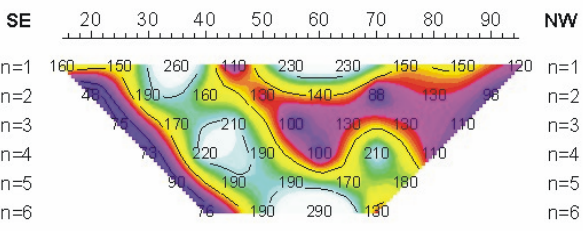

Resistividade Verdadeira

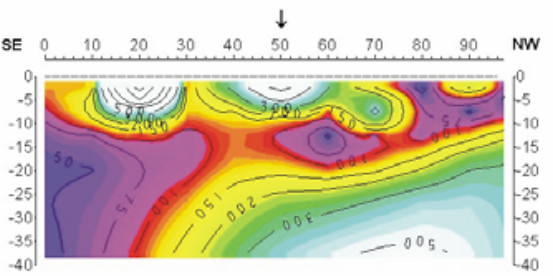

Cargabilidade Global Aparente

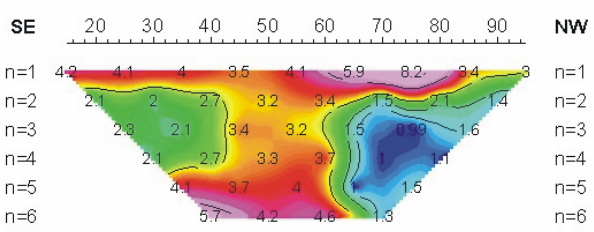

Cargabilidade Verdadeira

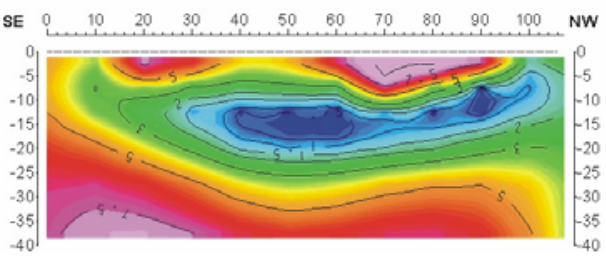

Figura 10 - Pseudoseções e modelos de resistividade (acima) e pseudoseções e modelos de cargabilidade (abaixo) das Linhas L5 e L15 (localização na Fig. 3).

de investigação do arranjo dipolo-dipolo, considerando 0 espaçamento $A B=M N=10$ metros. Já os resultados das sondagens elétricas verticais (Figs. 13 a 16), permitiram detalhar a estratigrafia geoelétrica da área, através de modelos, em geral, de quatro camadas. Note-se nestas ilustrações que os níveis saturados de baixas resistividades (aluviões e/ou fraturas alimentadoras/armazenadoras de água no substrato), com média de 20 metros, são compatíveis a maioria dos modelos 2D de resistividade e de cargabilidade (Figs. 10, 11 e 12). Por outro lado, a Figura 17 mostrou boa correlação entre a interpretação integrada das SEVs e os perfis litológicos dos poços P1 e P2.

0 perfil litológico de um poço desativado, contíguo a área do levantamento, mostra que a espessura da cobertura é da ordem de 5 metros, confirmando a interpretação geofísica e que as entradas de água ocorrem em vários níveis a partir de 7 metros abaixo da superfície até 94 metros de profundidade, esta última mais expressiva em termos de produtividade (Fig. 18).

A Figura 19 mostra a localização dos perfis (AB e CD) no mapa dos resíduos utilizado no processo de inversão e as Figuras 20 e 21 exibem tais perfis relacionando as anomalias observadas (resíduos) e o modelo correspondente. Observa-se nestas ilustrações que 0 baixo contraste de densidade e as espessuras de até 4 metros da estrutura modelada, a julgar pela discussão anterior, indicam a presença de material inconsolidado saturado 

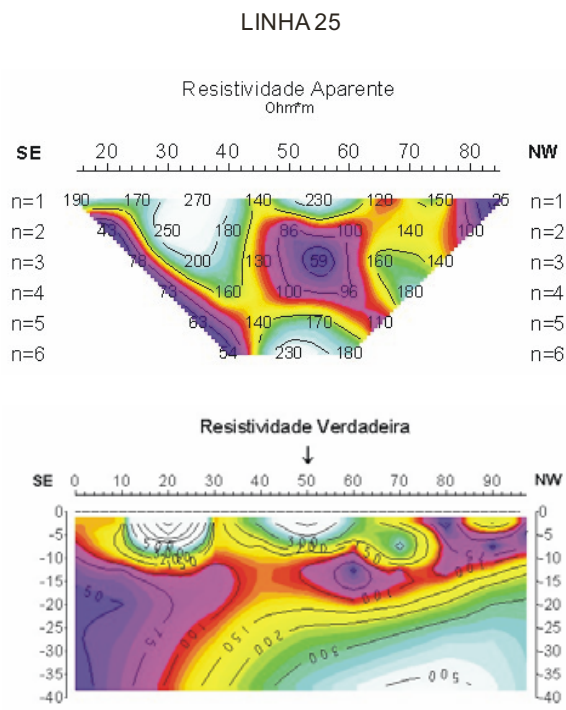

Cargabilidade Global Aparente

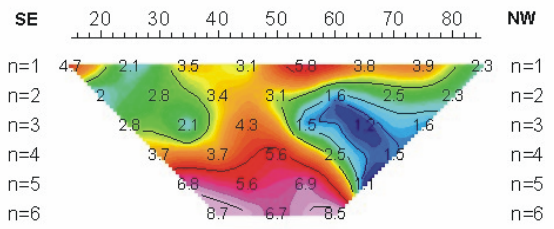

Cargabilidade Verdadeira

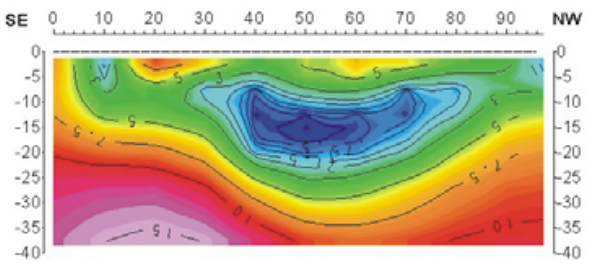

LINHA 95

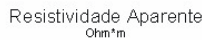

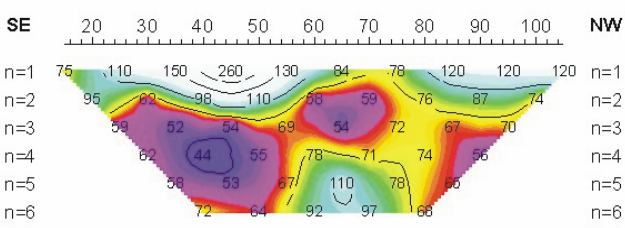

ResistividadeVerdadeira

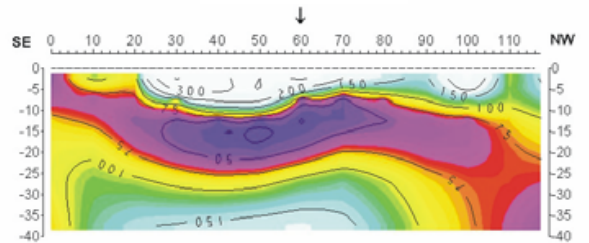

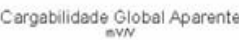

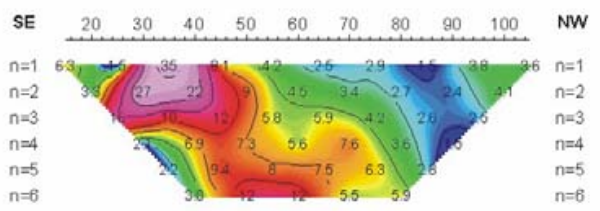

Cargabilidade Verdadeira

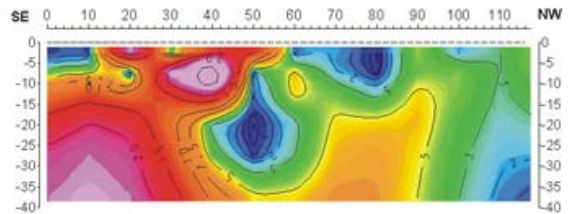

Figura 11 - Pseudoseções e modelos de resistividade (acima) e pseudoseções e modelos de cargabilidade (abaixo) das Linhas L25 e L95 (localização na Fig. 3).

em trato com alto grau de fraturamento.

Dados litológicos de sondagem direta indicam que as coberturas recentes são representadas por aluviões e/ou solos residuais/eluviais provenientes de intemperização da rocha carbonática original sotoposta.

\section{CONCLUSÕES}

A potencialidade dos métodos gravimétrico e eletrorresistivimétrico-IP em área específica do Sistema Aqǘfero Cárstico em Almirante Tamandaré-PR, foi avaliada através da sua capacidade de identificar tratos potencialmente exploráveis, quando sugere a presença de depósitos recentes saturados sobrepostos a estruturas armazenadoras de água. Ao mesmo tempo foi possível discutir as respostas dos métodos geofísicos em área de risco geotécnico, como a do Colégio Estadual Ambrósio Bini, o qual foi interditado como decorrência de colapso do terreno. Porém, 0 sucesso dos métodos depende de vários fatores, principalmente das dimensões e da complexidade das feições cársticas, o que dificultou a interpretação geofísica.

Os resultados apresentados pela gravimetria mostraram coerência quando comparados com os produtos dos levantamentos elétricos e com dados litológicos locais, principalmente derivados de sondagens rotativas.

A inversão gravimétrica e geoelétrica (resisitividade e IP) podem constituir ferramentas importantes na seleção de áreas de risco geotécnico, pois sugerem formas e profundidades dos cor- 


\section{LINHA 105}
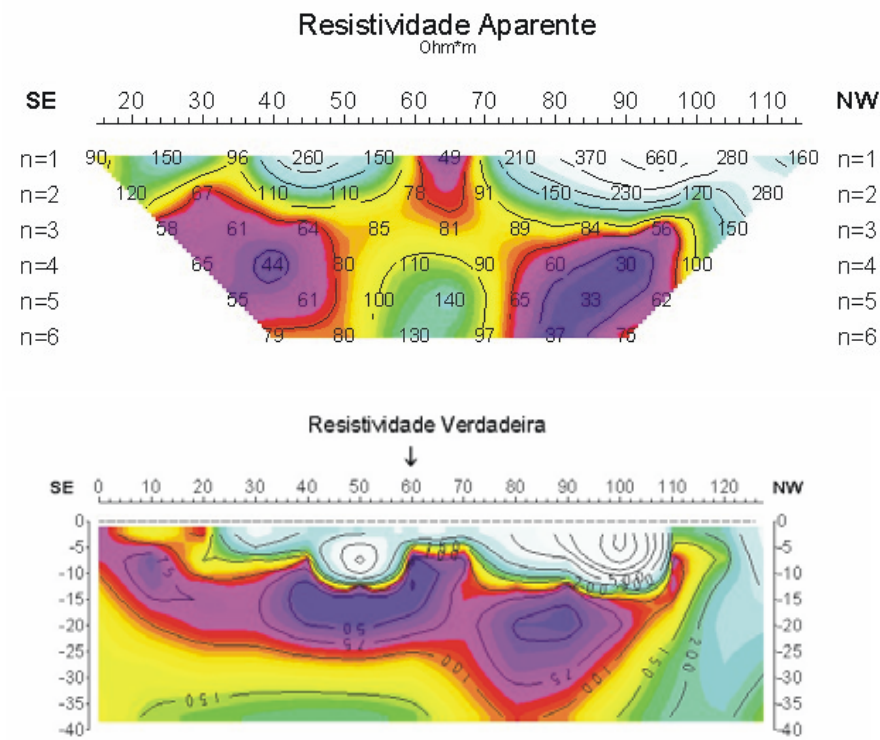

Cargabilidade $\underset{\operatorname{m} / / N}{\operatorname{Gl}}$ lobal Aparente
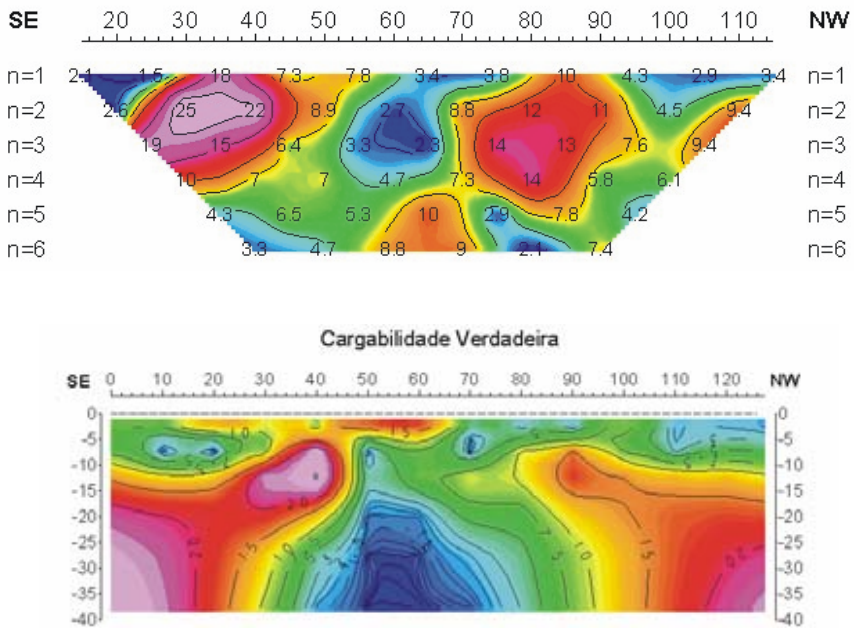

Figura 12 - Pseudoseções e modelos de resistividade (acima) e pseudoseções e modelos de cargabilidade (abaixo) da Linha L105 (localização na Fig. 3).

pos causadores das anomalias.

A aquisição dos dados geofísicos deve ser procedida de forma rigorosa, pois em regiões cársticas procuram-se feições que produzem apenas uma pequena variação nos campos elétrico e da gravidade. Assim, sobretudo na gravimetria, deve-se realizar um pré-processamento dos dados de campo de forma a identificar possíveis ruídos oriundos do processo de aquisição, evitando que no momento da interpretação tais ruídos sejam interpretados como resíduos. A decisão do espaçamento entre estações deve se adequar às dimensões da área e das estruturas que se deseja investigar. Tal decisão pode ser embasada em estimativas dos efeitos elétrico e gravimétrico provocados por determinado corpo (solução do problema direto).

Finalmente, este estudo de caso e outros em andamento, 


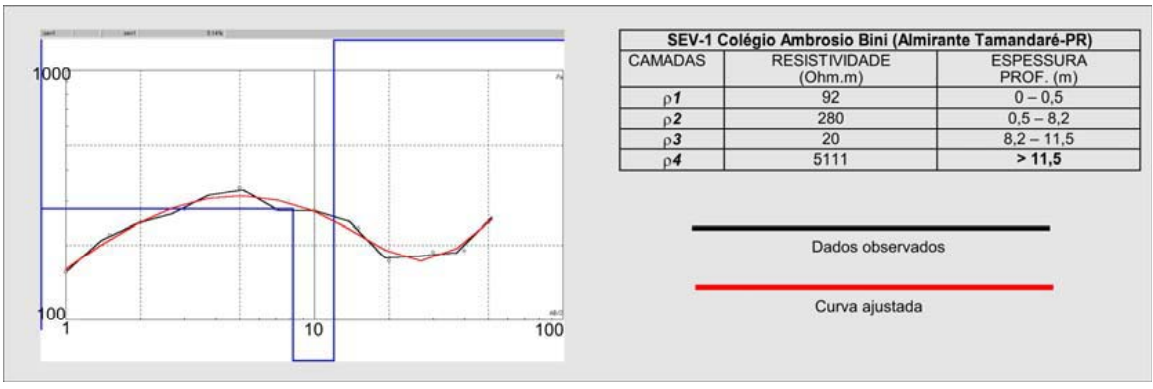

Figura 13 - Curva e modelo de profundidade da sondagem elétrica 1 (SEV-1, localização na Fig. 3).

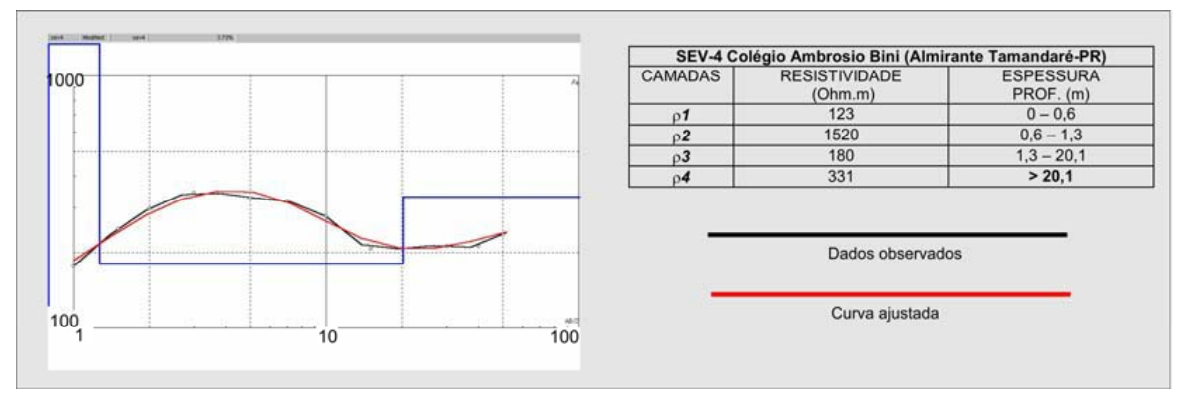

Figura 14 - Curva e modelo de profundidade da sondagem elétrica 4 (SEV-4, localização na Fig. 3).

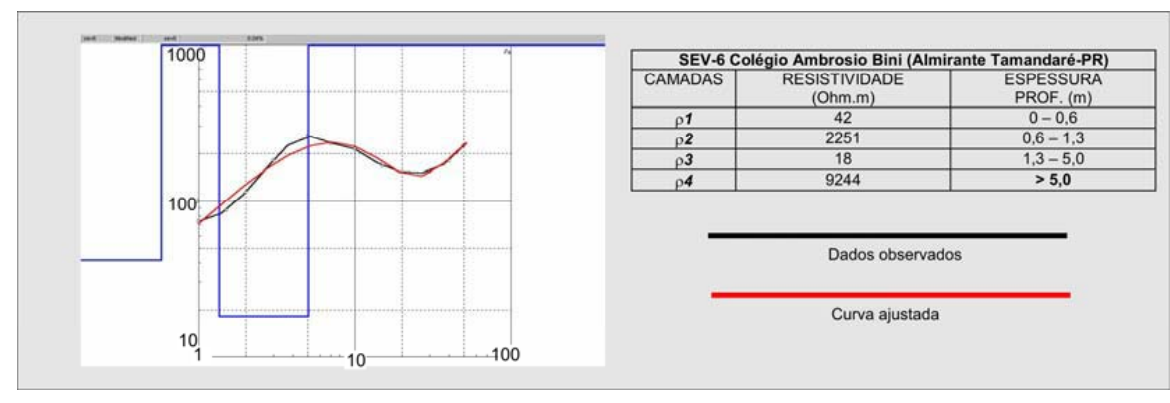

Figura 15 - Curva e modelo de profundidade da sondagem elétrica 6 (SEV-6, localização na Fig. 3).

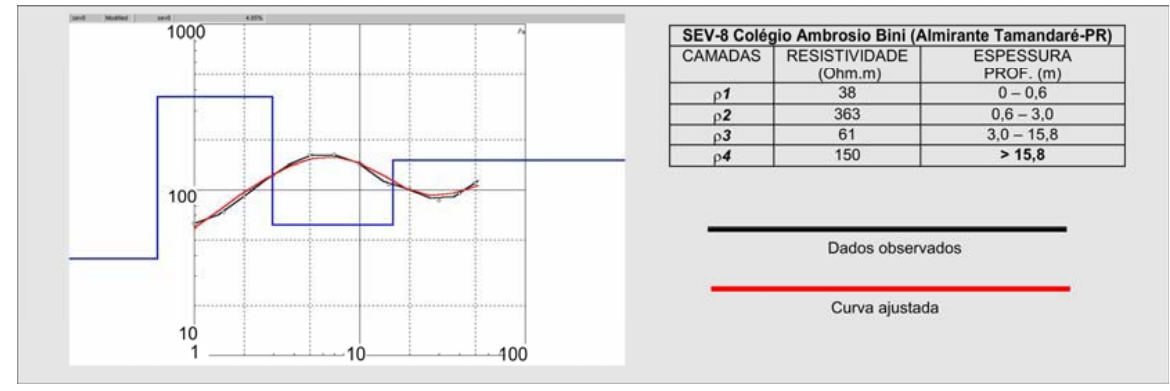

Figura 16 - Curva e modelo de profundidade da sondagem elétrica 8 (SEV-8, Iocalização na Fig. 3). 


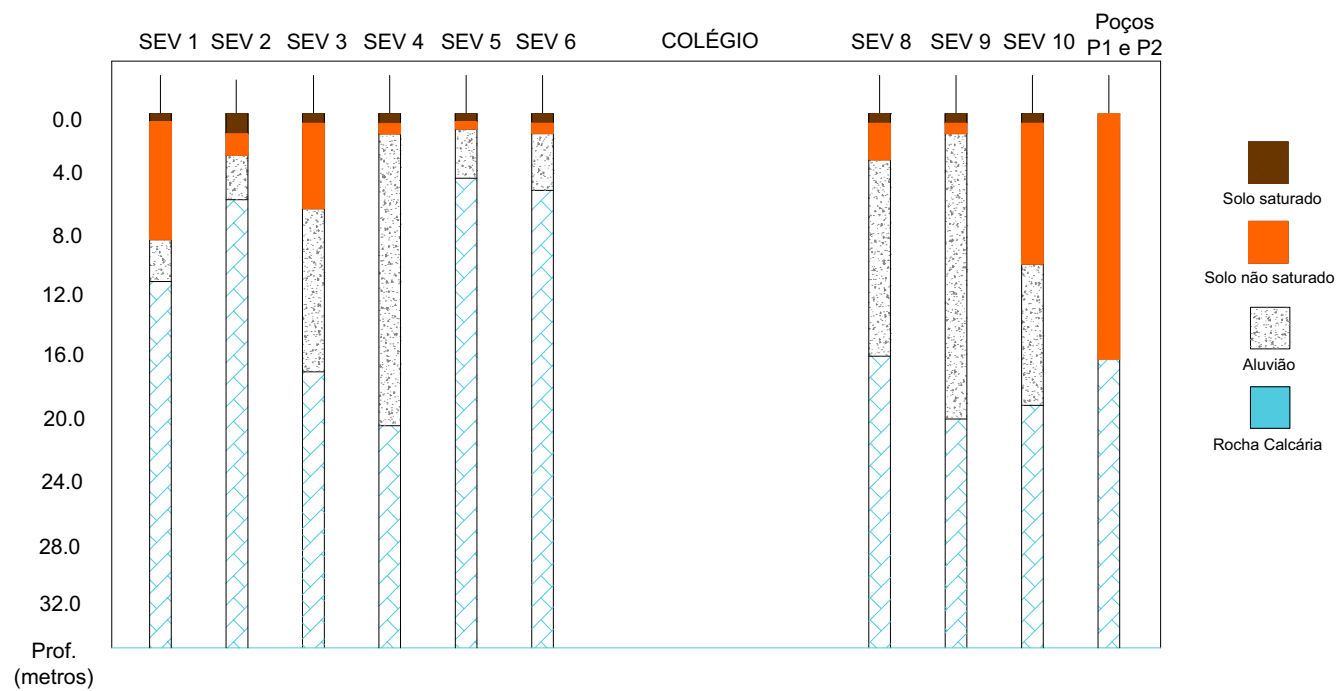

Figura 17 - Interpretação litológica das SEVs e sua comparação com os dados dos poços P1 e P2 (localização na Fig. 3).

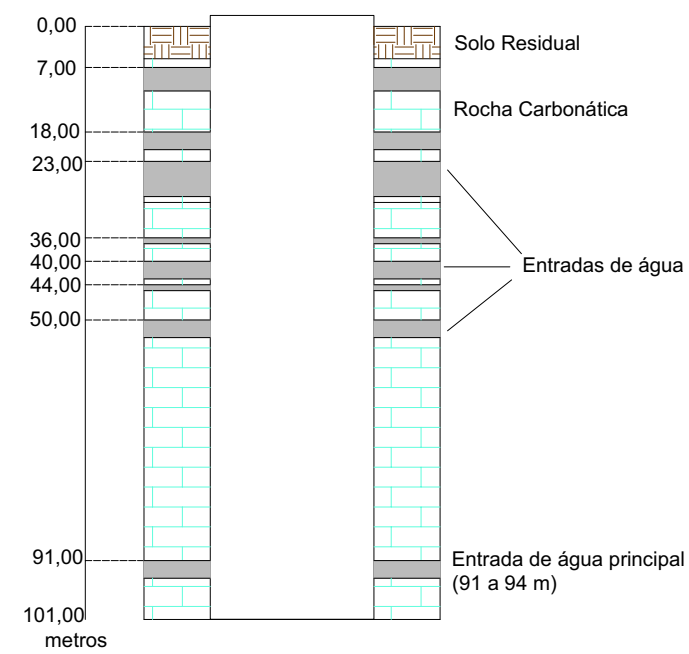

Figura 18 - Perfil litológico de poço desativado localizado próximo da área de estudo.

podem contribuir com as pesquisas multidisciplinares ora em desenvolvimento no Sistema Aqǘfero Cárstico em Almirante Tamandaré-PR.

\section{REFERÊNCIAS}

AL-RIFAIY IA. 1990. Land subsidence in the Al-Dahr residential area in Kuwait: a case history study. Quarterly Journal of Engineering Geology \& Hydrogeology, 23(4): 337-346.

ARZI AA. 1975. Microgravity for engineering applications. Geophysical Prospecting, 23: 408-425.

BRANSTON MW \& STYLES P. 2003. The use of time-lapse microgravity to investigate and monitor an area undergoing subsurface subsidence; a case study. Quarterly Journal of Engineering Geology \& Hydrogeology, 36(3): 231-244.

BRIGGS IC. 1974. Machine contouring using minimum curvature. Geophysics, 39(1): 39-48.

BUTLER DK. 1984. Microgravimetric and gravity gradient techniques for detection of subsurface cavities. Geophysics, 49: 1084-1096.

COLLEY GC. 1963. The detection of caves by gravity measurements. In: Geophysical Prospecting, 11: 1-9.

CORDELL L \& HENDERSON RG. 1968. Iterative three-dimensional solution of gravity anomaly data using a digital computer. Geophysics, 33(4): 596-601. 

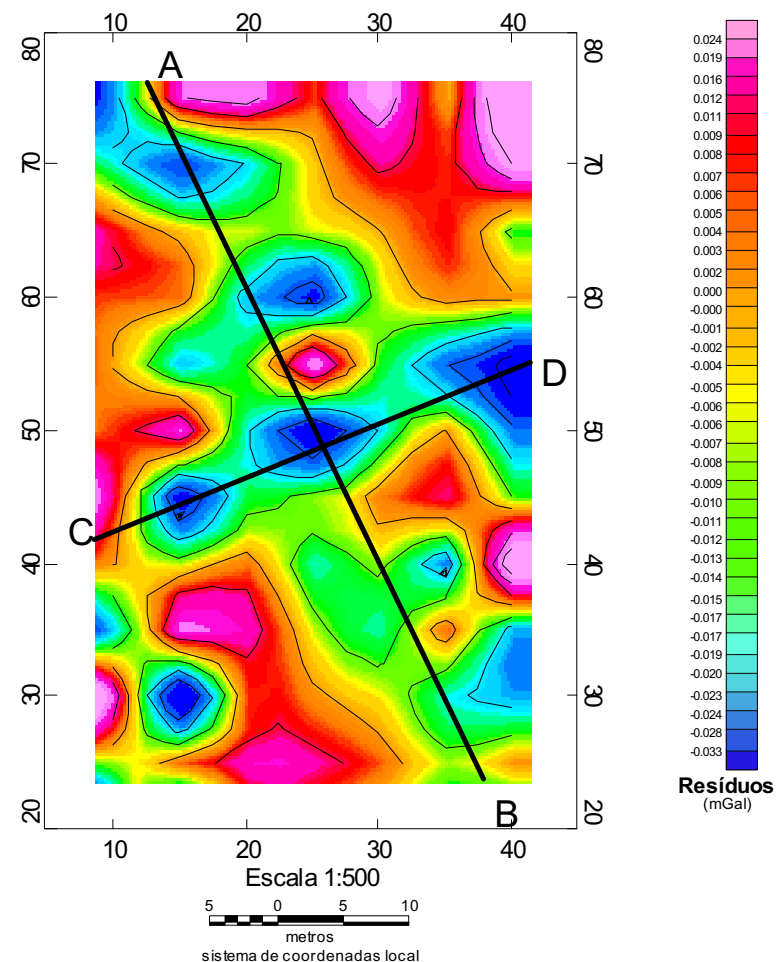

Figura 19 - Localização dos perfis no mapa de resíduos gravimétricos utilizados na inversão.

CRAWFORD NC. 2000. Microgravity Investigations of sinkhole collapses under highways. In: First International Conference on the Application of Geophysical Methodologies to Transportation Facilities and Infrastructure. St. Louis, MO. Proceedings.

DOURADO JC, MALAGUTTI FILHO W, BRAGA ACO \& NAVA N. 2001. Detecção de cavidades em arenitos utilizando gravimetria, eletorresistividade e GPR. Revista Brasileira de Geofísica, 19(1): 19-32.

FAJKLEWICZ Z. 1976. Gravity vertical gradient measurements for the detection of small geologic and anthropogenic forms. Geophysics, 41(5): 1016-1030.

GALLAS JDF \& AUGUSTO FILHO 0. 1999. Ensaios de eletrorresistividade, SP e IP em área de risco associado a colapso de terreno. In: Congresso Internacional da Sociedade Brasileira de Geofísica, VI., 1999, Rio de Janeiro. Anais eletrônicos... Rio de Janeiro: SBGf, CD-ROM.

KARST WATER INSTITUTE. What is Karst (and why is it important)? Disponível em: <http://www.karstwaters.org/kwitour/whatiskarst.htm>. Acesso em: 3 mar. 2006.

LISBOA AA. 1997. Proposta de metodologia para avaliação hidrogeológica do aqǘfero cárstico, compartimento de São Miguel. Curitiba 1997, 137 pp. (Dissertação de Mestrado - Curso de Pós-Graduação em Geologia, UFPR).
MINEROPAR. Minerais do Paraná SA. 2005. 0 Sistema Carste. Palestra realizada na Prefeitura Municipal de Almirante Tamandaré - PR em 12 abr. 2005 .

POLIDORO GFB. 2005. Karst na bacia do Alto Iguaçu, Região Metropolitana de Curitiba: Aspectos geológicos para a gestão da ocupação do solo e do uso do aqüífero na sub-bacia hidrográfica do rio Pacatuba em Almirante Tamandaré-PR. Curitiba, 122 pp. (Dissertação de Mestrado Curso de Pós-Graduação em Geologia, UFPR).

SHARMA PV. 1997. Environmental and engineering geophysics. Cambridge University Press, 475 pp.

TECHNOS INC. 2005. Characterizing Karst and Pseudokarst. Technical Report, 4: 12 pp. Disponível em: <http://www.technos-inc.com>. Acesso em: 02 fev. 2006.

TELFORD WM, GELDART LP \& SHERIFF RE. 1990. Applied Geophysics. Cambridge University Press, Cambridge, 770 pp.

TORGE W. 1989. Gravimetry. De Gruyter, Berlin, New York, 465 pp.

USGS. United States Geological Survey. 2005. Potential-Field Geophysical Software for the PC. Disponível em: <http://pubs.usgs.gov/fs/fs0076-95/FS076-95.html>. Acesso em: 13 maio 2005. 


\section{Perfil AB Ambrosio Bini}
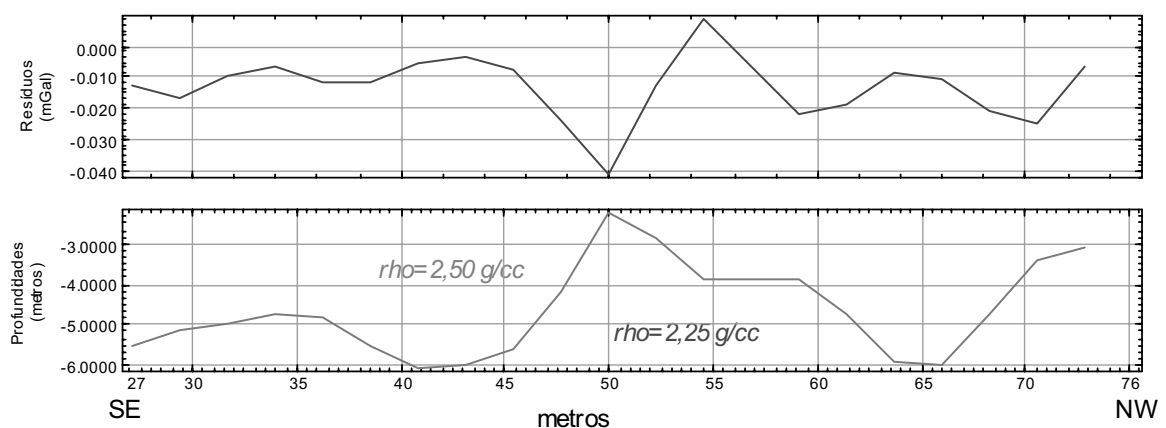

Figura 20 - Perfil gravimétrico residual AB e o modelo gerado por inversão (localização na Fig. 19).

\section{Perfil CD Ambrosio Bini}
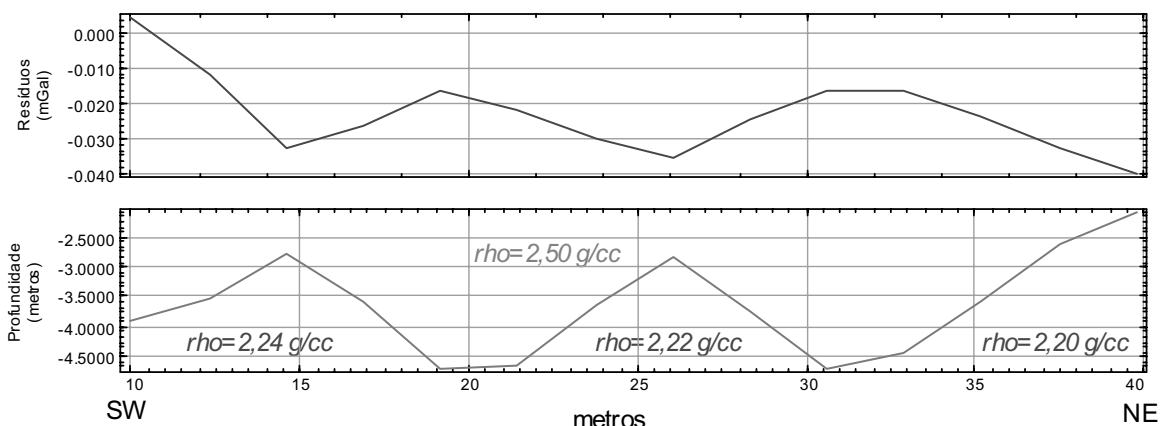

Figura 21 - Perfil gravimétrico residual CD e o modelo gerado por inversão (localização na Fig. 19).

\section{NOTAS SOBRE OS AUTORES}

Jair Silveira da Silva Junior (in memorian) obteve o bacharelado em Engenharia Cartográfica (UFPR-2003) e 0 mestrado em Geologia Ambiental (UFPR-2006). Desde 2005 ministrava, como Professor Substituto do Departamento de Geomática da UFPR, a disciplina de topografia para os cursos de graduação em engenharia civil e arquitetura da UFPR. Suas áreas de interesse envolviam geodésia física e geofísica aplicada à geologia ambiental. Faleceu tragicamente em 10 de dezembro de 2006.

Francisco José Fonseca Ferreira é Geólogo (UFPE-1970), Especialista em Geofísica Aplicada (UFBA-1974), Mestre e Doutor em Ciências (USP-1982; USP-1991), com atuação profissional na CPRM (1972-1980) e no IPT (1980-1990). Entre 1992-2005 foi Professor Adjunto e a partir de 2006 é Professor Associado do Departamento de Geologia da UFPR, onde ministra disciplinas de geofísica aplicada para os cursos de graduação e pós-graduação em geologia da UFPR. A partir de 1998 coordena o Laboratório de Pesquisas em Geofísica Aplicada - LPGA/UFPR. Áreas de interesse: geofísica aplicada à cartografia geológica e pedológica, exploração mineral e de águas subterrâneas e ao meio ambiente.

Rodoilton Stevanato é Geólogo (UFPR-1986), Mestre em Geologia Exploratória (UFPR-1998), com atuação na Mineração J.S. (1986-1992) e profissional autônomo (1993-1995). Desde 1995 é pesquisador do Laboratório de Pesquisas em Geofísica Aplicada - LPGA/UFPR. Áreas de interesse: geofísica aplicada à exploração mineral e de águas subterrâneas e ao meio ambiente. 